wonderful verse from Isaiah, "Nation shall not lift up sword against nation, never again shall they train for war." We studied the Koran, the Hebrew bible, and the gospels. We asked questions and others tried to answer them.

Up a narrow winding footpath behind the conference centre is a cemetery. Too many of those buried there have no living descendants. It is a Jewish cemetery. One grave of a man bears a memorial to his wife-deported 22 March 1942. On 22 March 1985 Jews, Christians, and Moslems climbed the hill together to offer a Jewish memorial service and to light a candle. Some people were moved to tears, Jews, Christians, and Moslems praying together that Auschwitz will never happen again.

My white coat pocket has acquired another book, Teach Yourself
German. My diary is filling up. A day to visit Mrs Kahn to learn how to wear a sari, some time to talk to Mrs Cohen who just happens to live round the corner, and we are going to visit a local mosque and have tea there one Sunday.

Everyone needs an escape valve when times are difficult. Perhaps doctors are scared to acknowledge their own weaknesses in front of a community that holds them in esteem. Perhaps if we were more open we would be better, stronger doctors.

I learnt a lot that week. Every moment was a challenge and the rewards were great-a deeper knowledge of the people and communities with whom I live and work and a greater knowledge of myself.

And, by the way, I think I believe in God again.

\title{
Appendicitis in Omsk
}

\section{DAVID TOMSON}

It seems hard to believe that it happened, as I sit here convalescing in an English country garden surrounded by the warmth of family and what $I$ hear is a fairly rare appearance of the sun. But a now well healed laparotomy scar, four drain holes, and a still open grid iron wound confirm that in fact two weeks ago, almost to the hour, I was lying on an operating table under the knive of a fine Georgian man with sparkling eyes and a good Cossack nose, called Goram. The place-Omsk, central Siberia, east of the Urals, USSR. But it doesn't really begin there.

It had long been the plan that while coming back on the TransSiberian Railway from three months in southern China, I would take an intermittent photographic panorama of half the world. Every four hours I would record the scene. I never finished it, but perhaps I could give you some word pictures that are as permanently fixed in my memory as ever my pictures are on celluloid.

Beijing (Peking) railway station: $7 \cdot 30$ on Wednesday morning, carriage 6, two doors from the Chinese restaurant car. My companions: Francis, a friend, a medical student, a smiling Buddha (Chinese food had done nothing to reduce his girth), a seven week intensive student of acupuncture, and John, a footloose Australian on his way to relations in Latvia. A spare bunk was piled high with Chinese scroll paintings, model acupuncture men, and other goodies we were hauling home.

Down the corridor were as varied a bunch of travellers as you could wish for. René, a Dutch version of Sherlock Holmes complete with twinkling eyes, enormous green cloak, and a long stemmed pipe. An itinerant Argentinian who, when offered beer, proceeded to pour it liberally on to his hair, claiming that it was much better than shampoo. (It didn't look as though he had done many trials, controlled or otherwise.) Fifty seven Germans, who had proudly spent twice as many dollars in 25 days rushing blindly round half the world as Jill had spent in eight months doing voluntary work in a leprosy hospital in Thailand, and finally six Finnish anthropologists, who turned out to be both excellent company and excellent hairdressers.

\section{First symptoms}

Click. The plains of Inner Mongolia, the eastern tip of the Gobi, the vast uplands of Outer Mongolia, Ulam Baator, the blue expanse

Ingleby, North Tees General Hospital, Hardwick, Stockton on Tees, Cleveland TS19 8PE

DAVID THOMSON, BA, BM, house officer of Lake Baijkal edged by melting ice floes, and the first of endless silver birch trees.

Click. A niggling stomach ache outside Irkutsk. No one recommended the Russian dining car so perhaps it was the Chinese friendship store's Spam. Nothing that a little acupuncture treatment wouldn't cure. Enter the thin, bearded medical student lying on the bottom bunk. Small silver needles placed in the webs between first and second toes, two larger ones lateral to the tibia two Chinese inches below the patella-Zusanli point-a general tonic point; another couple neatly inserted two cun from the navel and a couple more on Hegu in the hands. The Chinese cabin staff didn't bat an eyelid. Such activity is the fried rice and prawns of the TransSiberian. Unfortunately the pain didn't take much notice either.

Novosibirsk. "What about a doctor?" "No, it will turn out to be gastroenteritis." "I've just read the acute abdomen (with final exams three weeks away and having done no Western medicine for three months this was the first attempt at revision) and I don't think it's appendicitis." "No, you can't walk with appendicitis." (You see, the Trans-Siberian reaches parts other train rides leave alone.)

Four hours from Omsk, $1100 \mathrm{pm}$. Somebody's sign positive, somebody else's negative-guarding but not rigid. The pain was getting worse. Even the driver had caught a flavour of the drama, and we arrived in Omsk a quarter of an hour early. They had alerted the doctors. I was to be examined on the train.

\section{Russian operation}

I had heard that the Russian middle aged population shared a tendency with the Italians - that is, a propensity to spread-but this was ridiculous. Swathed in Siberian coats and scarves, the question was would she, the doctor, get into the carriage - head on, sideways, or with a run up? Like a champagne cork she teetered tantalisingly at the door before finally arriving in a flourish. Shades of Mervyn Peake, but this was real and so was the huge metal tool box out of which came an ancient stethoscope. There was no mistaking the slow thoroughness of my examination and no doubting the decision. I was to go to hospital in Omsk.

Rushing through the pale Siberian night, through Omsk - city of Dostoevsky's exile-closed city without a cathedral ("so the foreigners wouldn't be interested to visit it anyway"). Omsk-city of the most wonderfully caring and efficient nurses and doctors, city of the surgeons in chefs' hats. Omsk with Goram, who saved my life more or less.

Lying still and peacefully, I surveyed the Russian intensive care unit, clean and white, all reuseable. I felt safe and cared for. I had known for some time that for the patient a good nurse is worth 10 
competent doctors. How well I relearnt what I knew. And they never let me down. Galina, Svietnam, Lydia, Vladimir... After the removal of a perforated gangrenous appendix and one litre of pus I recovered slowly but surely-largely because of their love, care, and attention. But it wasn't as if the doctors cared any the less.

Each morning a gaggle of them would arrive. White coated and chef hatted they always asked, listened, smiled, reassured, and organised today's treatment. A central venous pressure line and intramuscular injections were the order of the day (in fact every day). Antibiotics, theophylline, and much that I didn't understand. I tried, "Is that metronidazole?" in sign language, but not content with that, I spent an hour a day staring out of the porthole of a hyperbaric oxygen cylinder eating Russian chewing gum, and I would finish the day having 20 small glass cups stuck to my back. (For the uninitiated, ask your grandfather what "cupping" is.)

Smiling and basic sign language served me well but certain Russian words needed no translating. The word for enema is as memorable as the large, orange, pear shaped contraption is effective: clysma-or to give it the full title-cataclysma. The word for "not OK" also seemed particularly appropriate, especially during the early days of paralytic ileus-blocha. (Actually plocha but I persistently used the former.) Some words aren't so easy, as my dear friend David found out. He was ringing Omsk from England on behalf of my parents who were convinced that I was slowly shedding this mortal coil, as was the old priest in Northumberland who was saying rosaries for me. David's Russian was good and he was getting on fine talking to the duty doctor until he was silenced with the immortal phrase, "We have inserted four tampons into him." Tampon is the Russian for drain.

\section{Experience gained}

A week after the operation. I was out of intensive care and reading a bizarre collection of English books brought for me by the two doctors who spoke English. Quietly recovering. Eight days later my father, having run the gauntlet of embassies, ambassadors, and numerous officials, arrived together with his guides and hosts, Nelly and Nikolai. Within a day they had organised our return trip: ambulance to the airport, flight to Moscow, ambulance across the city, and hopefully a British Airways flight home.

The last evening was spent giving and receiving presents: traditional wood carvings, Matryoska dolls, and a memorial book about Omsk from my band of surgeons. An evening of bonhomie and genuine warmth. I was sad to say goodbye but happy to be finally going home.

I learnt much when I was ill in Omsk and am learning more as I recover here. About how big an insult to the body an operation is, how important care and attention are, how horrible bedpans are, how impossible it is to flirt with someone who is giving you an enema, and what it means to have a loving family and girlfriend, but most importantly I learnt again that people are the same the world over. Full of the same ingredients of love, hate, honesty, deceit, and so on, that make up the human condition, and so it underlined again the horrifying madness of planning and paying for the destruction of another people. It underlines the dangers of ideology, any ideology -monetarism, capitalism, communism, social democracy-that ceases to strive to understand all the people of this ever shrinking world and attempt to live with them in balance. The same balance that my weedy body is gradually reclaiming.

\section{By a stroke of luck...}

\section{HERMAN ANKER}

Health professionals are often concerned with interventions to induce changes in people's lifestyles. At other times events of life intervene.

Certain critical events may be anticipated-for example, puberty, marriage, childbirth, and change of job-they are stormy enough, but social norms, education, and planning enable us to deal with them. Faced with the acute trauma of severe illness or the shock of bereavement, we are most often unprepared and defenceless without the tools of experience to help us. It is then the role of the professional helper to ease the passage through a critical phase of life.

Health professionals also are subject to the trauma of major events in life. I believe that their experience as patients may contribute facets useful to our understanding of the impact of acute illness on the process of rehabilitation. I therefore wish to share my experience of an illness that intervened dramatically in my life three years ago at the age of 49. At the time my wife and I were leading active and fulfilling professional lives. My work as a doctor was bringing me into contact with many health professionals, informally and at meetings. There were letters and memorandums to write, lectures to prepare, reports and journals to read. I was also active in international work as adviser of a health project abroad that entailed some travelling. For the past six months illness in the family had made considerable additional claims on our resources.

To relive and expose to others my experience of illness is both

Oslo City Health Department, 0165 Oslo 1, Norway

HERMAN ANKER, MD, MPH, assistant director, General Health Services painful and difficult. People close to me played a central part in the events to be described. While I attempt to give a personal account of the events, I also wish to protect the privacy of my family and friends.

\section{The startling stroke}

A late January evening; we are sitting in front of the fire of our peaceful living room. Suddenly I slump forward, hitting my head on the table. Lying on the floor, as if groping for some lost object, I feel saliva dribbling from my mouth, my voice is strange and indistinct. I don't know what hit me. Surely it will get better. I hear my wife calling a doctor friend: "Please come, Herman has had a stroke." My objections are firmly overruled. Strong arms lift me on to a stretcher. I cannot move the left side of my body. A young, female intern looks at the admission papers: "I recognise you. You used to be my doctor when I was a kid."

Wheeled into a darkened ward, I am put to rest in the bed nearest to the door by efficient nurses. A urine bottle is placed under the bedclothes, a glass of juice on the table. A string from the bell is attached to my pillow with a napkin to wipe the dribbling saliva. Holding on to my right hand, my wife leans over to kiss my drooling mouth and murmurs: "We'll manage, darling."

Six other beds are emitting human sounds; light snoring, coughs, an occasional fart, and the sound of men turning over in their sleep. I lie exhausted, longing for sleep, and lose track of time. My left side feels inert and heavy, a part of me that is present and yet absent. Like the vibrant string of a spent bow, all my willpower summons the fingers to move. In vain.

I never fall asleep lying on my back. Attempting to roll over on my left side, I nearly fall out of bed. Instead I try turning to the right and embark on the heavy task of shifting my lifeless limbs across the bed with the right arm. Imagine lifting heavy flour sacks from the floor while lying down. Now I feel a pressure in the lower abdomen and must prepare for another procedure. 